\title{
The Life of Dorothy Tiffany Burlingham and the Pediatric Psychoanalysis
}

\author{
Joo Hee Han, ${ }^{1}$ Sohyeon Yun, ${ }^{2}$ Sang Min Lee, ${ }^{3}$ Ram Hwangbo, ${ }^{4}$ Hyun Jin Jung, ${ }^{5}$ and Geon Ho Bahn 6 \\ ${ }^{1}$ Ifamilylove Clinic, Seoul, Korea \\ ${ }^{2}$ School of Medicine, Kyung Hee University, Seoul, Korea \\ ${ }^{3}$ Department of Psychiatry, Konyang University College of Medicine, Konyang University Hospital, Daejeon, Korea \\ ${ }^{4}$ Department of Psychiatry, Graduate School, Kyung Hee University, Seoul, Korea \\ ${ }^{5}$ Department of Psychiatry, Chuncheon National Hospital, Chuncheon, Korea \\ ${ }^{6}$ Department of Psychiatry, Kyung Hee University School of Medicine, Seoul, Korea
}

\section{Dorothy Tiffany Burlingham의 삶과 소아정신분석}

\author{
한주희 ${ }^{1}$ 윤소현 ${ }^{2} \cdot$ 이상민 $^{3} \cdot$ 황보람 $^{4} \cdot$ 정현진 $^{5} \cdot$ 반건호 $^{6}$ \\ 가족사랑서울정신건강의학과의원, ${ }^{1}$ 경희대학교 의학전문대학원, ${ }^{2}$ 건양대학교 의과대학 건양대학교병원 정신건강의학교실, ${ }^{3}$ \\ 경희대학교 대학원 정신건강의학과, ${ }^{4}$ 국립춘천병원 정신건강의학과, ${ }^{5}$ 경희대학교 의학전문대학원 정신건강의학교실 6
}

Dorothy Burlingham was born in October 1891 in New York. Her paternal grandfather, Charles Lewis Tiffany, was the founder of Tiffany \& Co., a New York jewelry company. Her father, Louis Comfort Tiffany, was a successful artist in the glass industry. Dorothy's relationship with her father was not stable. Her husband, Robert Burlingham, was an American physician who graduated from Harvard Medical School. Her husband was emotionally unstable which led to an intolerable situation in her marriage. Because of this, in addition to the health and behavioral problems of her older son, Bob, Dorothy hired psychoanalyst, Anna Freud, to treat Bob's asthma and bad behaviors. Mrs. Burlingham and Ms. Freud became excellent partners in the area of child psychoanalysis. They remained good friends for over 50 years. After World War II, Mrs. Burlingham became one of the founders of Hampstead nursery. She published several academic papers on the psychoanalysis of blind children and twins. However, she is relatively less known to the public compared to Ms. Freud. We reviewed herein two great women psychoanalysts from the perspective of their friendship. We recounted the works and the impact of Mrs. Burlingham on pediatric psychoanalysis.

Psychoanalysis 2016;27(2):42-53

KEY WORDS: Dorothy Burlingham · Anna Freud · Child psychoanalysis · Blind · Tiffany.

Received: March 6, 2016 Revised: March 21, 2016 Accepted: March 21, 2016

Address for correspondence: Geon Ho Bahn, MD

Department of Psychiatry, Kyung Hee University School of Medicine, 23 Kyungheedae-ro, Dongdaemun-gu, Seoul 02447, Korea

Tel: +82-2-958-8556, Fax: +82-2-957-1997, E-mail: mompeian@khu.ac.kr

서 론

1920년대에서 1930년대는 비엔나를 중심으로 정신분석 활동이 매우 활발하게 이루어지고 있었으며, Anna Freud는 소아 세미나를 주도하며 소아정신분석이라는 새로운 영역을 구축하고 있었다(Geissmann 등 1992). 당시 참여한 인물 중 에는 René Spitz, Willie Hoffer, Heinz Hartmann, Wilhelm

This is an Open Access article distributed under the terms of the Creative Commons Attribution Non-Commercial License (http://creativecommons.org/licenses/by-nc/3.0) which permits unrestricted non-commercial use, distribution, and reproduction in any medium, provided the original work is properly cited.
Reich, Ernst Kris 등이 있었고, Helen Deutsch, Anny Ka$\tan$-Rosenberg, Beate Rank 등의 여성 정신분석가들도 있었 다. 당시 Anna Freud는 학교와 육아에 정신분석 이론의 접목 을 시도하였다(Bahn 2011). 그러한 시도의 일환으로 Hietzing 학교를 설립하였다. 학교 운영에는 Peter Blos, Erik Homburger(훗날 Erik Erikson) 등과 그녀의 친구인 Eva Rosenfeld가 참여하였다. 한편, 비엔나의 불우 아동을 위해 시작한 Jackson nursery 사업을 함께 주도한 인물은 Dorothy Burlingham이다(Lynn과 Vaillant 1998).

Dorothy Burlingham은 소아정신분석의 선구자인 Anna Freud의 학문적 동반자이자 인생의 동반자이다(Bahn 2011). 
두 사람은 50 여 년간 함께 소아정신분석 분야를 개척하였으 며, 자신들만의 영역을 구축하였다. Anna Freud의 이론과 업적은 여러 학자들에 의해 계승되었다. 제 2 차 세계대전 후 그녀가 설립하고 운영하였던 Hamstead nursery는 1952년부 터 Hamstead Clinic으로 이용되었고, 1984년 Anna Freud Center로 개명되어 현대 정신분석의 중추적 역할을 담당하 고 있다. 동시대에 함께 활동하였음에도 불구하고, Dorothy Burlingham의 삶에 관한 자료는 Anna Freud에 비해 미미 하다. 그녀가 생전에 작성하였던 논문과 그녀의 친손자인 Michael John Burlingham이 출판한 전기(Burlingham 1989)를 제외하면 Dorothy Burlingham의 이론이나 역할에 대한 기 록을 찾아보기 어렵다.

본 논문에서는 Anna Freud(이하 Anna)와 함께 소아정신 분석 영역을 개척하였던 Dorothy Burlingham(이하 Dorothy)의 삶을 재조명해 보고자 한다. 그녀가 집필하였던 수십 편의 논문과 학술적 활동에 초점을 맞추기보다는 그녀의 출 생부터 죽음까지 연대기적 관점에서 본 논문을 작성하였다. 그녀는 뉴욕에서 출생하였지만, 30 대 초반에 비엔나로 이주 한 뒤부터 87세에 사망할 때까지 50여 년을 Anna와 함께 생 활하였다(Bahn 2011). 그녀가 비엔나로 이주한 이유는 큰아 들 Bob의 치료를 위해서였다. Dorothy는 정신분석 치료를 받는 아이의 부모로서 Anna와 친분을 쌓아가던 중 정신분 석학에 매료되어 정신분석에 입문하였다. 이렇듯 Dorothy 와 Anna의 만남은 Dorothy의 삶을 바꾸어 놓은 중요한 사건 이다. 따라서 본 논문의 전개 역시 그녀가 Anna를 만나기 전 과 그 후로 나누어 기술하였다.

\section{본 론}

\section{Anna Freud를 만나기 전의 삶(1891 1925): 미국 뉴욕}

\section{출생 및 어린 시절}

Dorothy는 1891년 11월 미국 뉴욕에서 유리공예가인 아버 지 Louis Comfort Tiffany와 그의 두 번째 부인 Louise Wakeman Knox(별명 Mama Lou)의 막내딸로 태어난다(Table 1). 아버지는 첫 번째 결혼으로 두 명의 딸과 한 명의 아들, 그리고 두 번째 결혼으로 네 명의 딸까지, 총 일곱 명의 자녀 가 있었다. 아버지는 막내가 아들이기를 바랐으나 딸이었고, 그 아이가 Dorothy였다. Dorothy가 출생한지 6개월 후, 그녀 의 언니 Annie Olivia Tiffany(1888 1892)가 사망하고 Dorothy는 쌍둥이 언니 Louise Comfort Tiffany(1887 1974), Julia de Forest Tiffany(1887 1973)와 어울려 자랐다. 같은 옷을 입고 무엇이든 함께 하는 쌍둥이 언니들 틈에서 Doro- thy는 늘 외톨이였다. 언니들과 어울리기 위해 항상 "나도(me too)"라고 외쳤기에 Dorothy에게는 “me-too"라는 별명이 생겼다.

Dorothy는 어린 시절 가까운 사람들의 죽음을 많이 경험하 였다. Dorothy가 채 한 살이 되기도 전에 언니 Annie가 사망 하였으며, 여섯 살 때는 외할머니 Harriet Tiffany, 열 살 때는 외할아버지 Charles Lewis Tiffany가 세상을 떠났다. 12세에 는 어머니가 사망하였고, 16살에는 언니 Hilda(1897 1908)를 잃었다. 유년기에 가족의 죽음을 목격한 것은 Dorothy의 정 서발달에 영향을 주었다. 특히 어머니의 죽음은 Dorothy에 게 충격이었고, 그녀가 어두운 성격이 되는 원인으로 작용하 였다. 대장암으로 투병 생활을 하던 어머니는 모르핀으로 통 증을 조절하며 힘겹게 버티었는데, 이 모습을 지켜보는 것은 Dorothy에게 큰 고통이었다. 후에 Dorothy는 "나는 어머니가 돌아가신 게 다행이라고 생각했었다. 왜냐하면 어머니가 더 이상 고통받지 않아도 되기 때문이다.”라고 하였다. 어머니는 자제력이 있는 성격으로 딸들의 고등교육을 지지한 반면, 그 녀의 아버지는 자주 화를 내고 언성을 높였으며 딸들의 고등 교육에 반대하였다. 위와 같은 이유들로 어머니와 아버지는 갈등을 겪었고, 그로 인해 Dorothy는 아버지에 대한 부정적 인 견해를 갖게 되었으며, 어머니의 죽음 역시 아버지 탓이라 여겼다(Burlingham 1989).

\section{교 육}

Dorothy의 아버지가 딸들의 고등교육을 반대하기는 하였 으나, 자신이 운영하는 유리 회사에 여자 직원을 고용했다는 점을 미루어 볼 때 여성의 사회 진출 자체를 반대한 것은 아 니라고 생각된다. Dorothy의 유일한 오빠인 Charles Lewis 2 세는 Yale 대학을 갓 졸업한 후 'Tiffany \& Company'에 근무 할 당시 “유리공예가인 아버지는 고등교육을 받지 못했고, 자 신보다 딸들의 교육수준이 높은 것을 받아들일 수 없어 딸 들의 고등교육에 반대한 것 같다.”라고 언급하였다(Burlingham 1989). 일례로 Dorothy와 쌍둥이 언니들은 Brearley 초 등학교에 다녔는데, Dorothy는 수학과 언어, Julia는 의학, Comfort는 예술과 문학에 재능을 보였다. 하지만 아버지는 '내 딸 중에 의사가 되는 사람은 없을 것'이라며 강하게 반대 한다. 이와 달리 어머니는 딸들의 교육에 적극적인 입장으 로, 부부는 이 문제로 자주 다투었다. 이런 상황에서 Dorothy는 아버지에 뜻에 반하여 기숙학교에 진학한다. Dorothy 의 기숙학교 진학에 가장 큰 영향을 준 인물은 어머니의 오랜 친구인 Julia de Forest이다. 그녀는 Mama Lou가 사망한 그 해 여름 Dorothy와 쌍둥이 언니들을 본인의 오빠인 Robert de Forest와 올케인 Emily 집에 머물도록 한다. 이는 Doro- 
Table 1. Bibliography of Dorothy Burlingham and Anna Freud before they had met

\begin{tabular}{|c|c|c|c|c|}
\hline Year & Dorothy Burlingham & Age & Anna Freud & Age \\
\hline 1891 & $\begin{array}{l}\text { November; born in Lennox Hill Mansion, } \\
\text { New York, USA }\end{array}$ & 0 & & \\
\hline 1895 & & 4 & December 3; born in Vienna, Austria & 0 \\
\hline 1897 & Death of grandmother, Harriet Tiffany & 6 & & 2 \\
\hline 1901 & $\begin{array}{l}\text { Marriage of her brother Charles Lewis II with } \\
\text { Katrina Ely }\end{array}$ & 9 & & 5 \\
\hline 1902 & Death of grandfather, Charles Lewis Tiffany & 10 & & 6 \\
\hline 1904 & Death of mother, Louise Wakeman Knox & 12 & & 8 \\
\hline 1905 & $\begin{array}{l}\text { Sister Comfort and Julia graduate Brearley school } \\
\text { Dorothy attends St. Timothy's school }\end{array}$ & 13 & & 9 \\
\hline 1908 & Death of sister Hilda & 16 & & 12 \\
\hline 1909 & & 17 & Starts child psychoanalysis (little Hans' case by S. Freud) & 13 \\
\hline 1910 & Graduate from St. Timothy's school & 18 & & 14 \\
\hline 1912 & & 20 & Graduates from Cottage lyceum & 16 \\
\hline 1914 & September 14, marries to Dr. Robert Burlingham & 22 & $\begin{array}{l}\text { Visits London to learn English } \\
\text { Passes the test for preliminary teacher course }\end{array}$ & 18 \\
\hline 1915 & Birth of her first son Robert ("Bob") Burlingham Jr & 23 & Teacher training & 19 \\
\hline 1916 & Illness of her husband, son, and father-in-law & 24 & Teacher training & 20 \\
\hline 1917 & $\begin{array}{l}\text { Birth her second child Mary Tiffany ("Mabbie") } \\
\text { Burlingham }\end{array}$ & 25 & $\begin{array}{l}\text { Teacher training } \\
\text { Works as a teacher at Cottage lyceum which is her } \\
\text { alma mater }\end{array}$ & 21 \\
\hline 1918 & Robert suffers from a second nervous breakdown & 26 & $\begin{array}{l}\text { Participates in congress for the first time } \\
\text { Sigmund Freud analyzes his daughter until } 1922\end{array}$ & 22 \\
\hline 1919 & Birth of Katrina Ely ("Tinky”) Burlingham & 27 & Works as a teacher at Cottage lyceum & 23 \\
\hline 1920 & Leaves Dr. Robert & 28 & Death of her sister Sophie by pneumonia & 24 \\
\hline 1921 & Birth of Michael ("Mikey”) Burlingham & 29 & & 25 \\
\hline 1923 & & 31 & Sigmund Freud gests a jaw cancer & 27 \\
\hline 1924 & & 32 & November; meets her friend, Eva Rosenfeld & 28 \\
\hline 1925 & $\begin{array}{l}\text { Leaves to Geneva } \\
\text { Meets Anna Freud in Vienna }\end{array}$ & 33 & Meets Dorothy Burlingham & 29 \\
\hline
\end{tabular}

thy의 아버지와 아이들이 함께 살지 않도록 하여 아이들에게 미치는 아버지의 영향력을 최소화하기 위함이었다. Julia는 Mama Lou가 원하는 방식으로 아이들이 성장할 수 있도록 신경을 썼다. 1905년 6월 쌍둥이 언니 Comfort와 Julia는 Brearley 학교를 졸업하고 아버지의 뜻에 따라 더 이상의 교육 과정을 포기한 채 결혼하여 가정을 꾸릴 준비를 한다. 하지만 Dorothy는 기숙학교에 입학하여 아버지의 영향력에서 벗어 나는데, 이때 아버지 설득에 결정적인 역할을 한 인물이 앞 서 언급한 Julia이다. Julia는 미혼인 친한 친구 Kilham 박사 와 함께 살았으며, 그들의 지적 동반 관계는 Dorothy가 성인 이 된 후 Anna와의 관계를 형성함에 있어 모델이 되기도 한 다(Burlingham 1989).

Dorothy는 1905년 St. Timothy's 학교에 입학하여 5년간
기숙학교 생활을 한다. 기숙학교 재학 초기, Dorothy는 적응 하지 못해 몹시 괴로워했고, 아버지에게 집으로 돌아가고 싶 다고 말하지만 거절당한다. 아버지 본인 역시 젊은 시절 아버 지 뜻을 거스르고 유리공예가가 되었는데, Dorothy가 기숙 학교에 진학한 것이 아버지에게 자신의 유년기 모습이 떠오 르도록 했을 것이다. 아버지의 이러한 태도에 Dorothy는 기 숙학교에 남아 잘 해내기로 결심한다. 오전에는 프랑스어를 사용하고 오후에는 독어와 영어를 사용하는 학교 방침 덕분 에 Dorothy는 다양한 언어를 익힐 수 있었다. Dorothy는 학 교에서 주는 학업 우수상을 받기 위해 부지런히 공부했다. 뿐만 아니라, 축구와 농구 등 운동도 열심히 하여 그녀가 속 한 농구 팀을 승리로 이끌고 학업과 운동에 모두 뛰어나다는 평을 얻었다. Dorothy는 5년간 기숙학교 생활을 마치고 1910 
년 봄에 집으로 돌아와 향후 4년간 집에서 여유로운 생활을 누렸다. 이 무렵 Dorothy의 쌍둥이 언니들은 1910년과 1911 년, 각각 결혼하고 집을 떠났다.

\section{결 혼}

Dorothy의 연애와 결혼에 대해서는 알려져 있는 자료가 많 지 않다. 남편 Robert Burlingham(1888 1938)(이하 Robert) 은 Charles Culp Burlingham(1858 1959)과 Louisa Weed Lawrence(1863 1937)의 막내아들이다. Robert에게는 형 Charles Burlingham(1884 1979)과 누나 Anne Hoe Burlingham(1886 1974)(별명 Nancy)이 있었다. 형 Charles는 Harvard 법대를 졸업하여 철도회사에서 변호사로 일하였다. Dorothy의 남편 Robert는 Harvard 의대 졸업 후 Columbia 대학병원 외과에 지원한 의사였다. Robert는 Dorothy보다 네 살 연상이었고, 감수성이 풍부하고 외모 또한 훤칠하였 다. 하지만 Robert는 장인이 될 Dorothy의 아버지와 관계가 원만하지 못하였다. 장인이 Dorothy와의 교제를 반대하자 Robert는 이 갈등 상황을 피하기 위해 1년간 파나마 운하 근 처의 Ancon 병원에서 외과 인턴 과정을 밟는다. 아버지 Louis는 Dorothy와 Robert가 몇 년 후에도 교제를 원한다면 결 혼을 허락해 주겠다고 하였고, 그들은 1914년에 결혼하였다.

Burlingham 부부는 Robert가 당시 근무하던 Roosevelt 병원과 가까운 아파트에서 결혼 생활을 시작한다. 결혼한지 두 달 후 Dorothy는 첫째 아이를 임신하게 되고 1915년 8월 29일 큰아들 Robert Burlingham Jr(별명 Bob)를 출산한다. 이때까지는 결혼 생활이 순탄한 듯 보였으나, 1916년 남편 의 신경쇠약이 발생하면서 불행이 시작된다. 남편뿐 아니라 시아버지 역시 신경쇠약으로 고통받는다. 첫째 아들 Bob은 태어난 지 6개월 만에 습진이 생기고 천식 발작까지 발생하 여 할아버지, 아버지, 아들 3대가 모두 허약해진다. 시아버지 의 신경쇠약은 1916년이 마지막이었지만, 남편 Robert의 경 우 죽을 때까지 만성적으로 재발하고 Dorothy가 견디기 힘 든 상황에 이른다. 이 무렵 시어머니가 시댁 근처로 이사를 오 도록 요구하였고 Burlingham 부부는 Murray Hill로 이사하 였다. 이후부터 시부모님들과의 교류가 많아지면서 여러 가 지 갈등상황을 겪게 되는데, 이런 갈등들을 겪으며 Dorothy 는 남편의 곁을 떠나기로 결심한다.

\section{남편과의 별거}

Dorothy가 별거를 결심하게 된 이유는 크게 두 가지로 볼 수 있다. 첫 번째 이유는 시부모님과의 갈등이며, 두 번째는 남편 Robert의 신경쇠약이다. 시댁 근처로 이사를 한 후 Dorothy는 시어머니가 참석하는 다과회에 초대받았다. Doro- thy는 당시 유명한 유리예술가 Louis Comfort Tiffany의 딸 이었고, 시어머니 또한 예술인이 많은 집안에서 성장하여 예 술 분야에 조예가 깊었다. 다과회에 참석하는 사람들은 Dorothy가 예술 분야에 대해 통찰력이 있는 이야기를 하거나 지식이 많기를 기대하였지만 그녀는 그 기대에 부응할 수 없 었고, 스스로 며느리로서 실패했다는 기분을 느끼게 된다(Burlingham 1989).

하지만 Dorothy와 시부모님 사이의 갈등이 심화되는 가장 큰 사건은 유모에 대한 입장 차이였다. Dorothy는 유년기에 무관심한 유모에게 맡겨졌던 경험이 있었고, 이 때문에 그녀 의 자식을 돌보는 유모 문제에 있어서 예민했다. 시아버지의 기록에 따르면, Dorothy가 고용한 유모는 Bob을 옷장에 가 두어 울음을 그치게 하는 방식으로 훈육하였다고 한다. 이를 목격한 시부모님은 그 유모를 해고하지만, Dorothy는 본인 이 신뢰하는 유모를 해고한 것을 받아들이지 못했다. 후에 Dorothy는 이 유모의 추천서를 써주며 다른 일자리를 구하는 것을 도와주었고, Dorothy의 이러한 행동은 시부모님에 대 한 반항으로 비추어졌다. 이로 인해 Dorothy와 시부모님과 의 갈등은 더욱 깊어졌다. Dorothy와 남편 Robert의 관계 역 시 원만하지 못했다. Robert의 증상으로 짐작해 보면 그의 신 경쇠약은 오늘날 질병관으로 보면 조울증(manic depressive disorder)이었다. Robert의 이모 Mellie와 외할아버지 역시 정신질환을 않고 있었으므로 그의 조울증은 유전질환인 것 으로 생각된다. Roosevelt 병원에서 인턴 과정을 마친 Robert 는 임상병리학 분야에서 연구 활동을 하다가 미국이 제 1 차 세계대전에 참전하자 군대에 자원해 의사로서 일하기도 한 다. 이 시기에 Dorothy는 둘째 아이인 Mary Tiffany Burlingham (1917년 5월 1일생)(별명 Mabbie), 셋째 아이인 Katrina Ely Burlingham(1919년 3월 27일생)(별명 Tinky)을 출산했 다. Dorothy는 남편의 자기통제능력 상실이 자녀들에게 부 정적인 영향을 미친다고 판단하였다. 남편에 대한 책임감보 다 아이들에 대한 책임감이 우선이었던 Dorothy는 남편과의 별거를 결심하고 막내인 Michael Burlingham(별명 Mikey) 을 출산하기 전인 1921년 5월 16일, 남편을 떠났다.

\section{별거 후 생활 및 제네바로 떠남}

Dorothy는 남편과 별거한 1921년부터 비엔나로 떠나는 1925년까지 약 4년간 아버지 집에 머물며 자유로이 보냈다. 그녀는 세 명의 자녀를 유모에게 맡긴 후, 네 번째 아이 Mikey 를 출산하기 위해 Marlborough에 있는 Alfred de Forest의 집으로 갔다. MIT 공대 교수였던 Alfred는 Dorothy의 쌍둥 이 언니들과 동갑내기 친구였는데, Dorothy는 Alfred를 무 척 따랐다. Alfred와 그의 부인 Izette는 신생 학문인 정신분 
석학에 관심이 많았다. Dorothy 역시 남편 Robert와 아들 $\mathrm{Bob}$ 의 문제를 겪으며 정신분석학에 관심을 갖게 되었다. 1921년 가을 Dorothy는 Joy Gilder(쌍둥이 언니 Comfort의 4 명의 자식 중 첫째로 Bob과 마찬가지로 천식을 않았음)와 함께 건조한 지역인 아리조나 주 투산으로 떠났다. 1923년에 는 네 명의 자녀와 함께 스위스에 갔다가 1924년 다시 투산 으로 돌아오는데, 이때 네 자녀의 나이는 각각 9살, 7살, 5살, 3살이었다. 이때까지 자녀들 중 아무도 학교에 다니고 있지 않았고, Dorothy는 어딘가에 정착하여 아이들의 교육을 시 작해야 할 때라고 생각하였다. Izette는 Dorothy를 코네티컷 주 스트라트포드로 초대하여 그곳에서 자녀들을 학교에 보 낼 수 있도록 도와주었다. 아마도 이곳이 Dorothy가 처음 정 신분석을 경험한 장소로 추정된다. 이 당시 Otto Rank가 미 국으로 건너와 강의를 하였는데, Dorothy는 이 강의에 참석 하였다. 천식 환자의 정신분석학적 치료 강의를 들으며 큰아 들 Bob을 떠올렸다. 동시에 Sigmund Freud의 딸 Anna Freud가 비엔나에서 소아정신분석을 성공적으로 해내고 있다 는 소식을 접하게 되자, Dorothy는 비엔나 행을 결심한다. 한 편 Izette de Forest도 Freud의 제자가 되어 정신분석을 배우 기 위해 1925년 1월 부다페스트로 떠날 계획을 세우고 있었 다. 이 역시 Dorothy의 비엔나행 결정에 큰 역할을 했을 것이 다. 때마침 Dorothy의 미국인 친구 Ruth와 Arthur Sweetser 가 제네바에 영어를 사용하는 아이들을 위한 국제 학교를 설 립하고 Dorothy와 네 자녀를 초대하였다. 스위스를 여행한 경험이 있던 Dorothy는 비엔나에 가기 전 제네바에 잠시 머 물며 친구들이 만든 학교에 네 자녀를 보냈다. 1925년 5월 1 일, Mabbie의 여덟 번째 생일에 Dorothy와 네 자녀는 비엔 나로 떠났다. "내가 비엔나로 간 이유는 전적으로 Bob 때문 이다. Bob은 정신적으로 어려움을 겪고 있었고 정신분석이 꽤 효과가 있다고 들었기 때문에 내가 비엔나에 있는 것이 다."(Burlingham 1989). 즉, Dorothy가 비엔나에 간 이유는 큰아들 Bob의 정신분석을 위해서였으며, 6 12개월 정도 그 곳에 머물고 돌아올 생각이었다. 하지만 비엔나에서 평생 친 구 Anna를 만나게 되고 유럽에 정착하여 남은 생을 보냈다.

\section{Anna Freud를 만난 후의 삶(1925 1979): 비엔나 및 런던}

\section{Anna Freud와의 만남}

Anna는 Dorothy가 태어난지 4년 후인 1895년에 출생하 였다(Table 1). Anna는 당시 정신분석의 대가 Sigmund Freud의 막내딸이자 아버지의 학문적 발자취를 이은 유일한 자녀였다. Anna는 아이들을 좋아해서 본인이 졸업한 초등학 교에서 교사로 일했다. 그러던 중 아버지 Sigmund Freud에게
정신분석을 받고 소아정신분석학에 관심을 갖게 된다. 1921 년 처음으로 소아정신분석 치료를 시작하고 1925년에는 비 엔나 정신분석연구소에서 소아분석기법을 가르쳤다(Bahn 2011). 이때가 Dorothy와 Anna의 운명적인 만남이 이루어 진 해이다.

1925년 Dorothy와 네 자녀는 제네바에 도착하여 Dorothy 의 친구인 Sweetser 부부가 설립한 국제학교에 다녔다. 제네 바에 도착하고 몇 주 후, Dorothy는 Anna가 있는 비엔나를 방문하여 아들 Bob의 정신분석에 대한 약속을 받고 돌아왔 다. 그해 가을, Dorothy 가족은 저택을 빌려 비엔나로 이사를 하고 Dorothy 본인과 Bob의 정신분석을 시작하였다. Dorothy의 정신분석은 Sigmund Freud의 동료 Theodor Reik가 담당하고 Bob의 치료는 Anna가 직접 맡았다. 곧 Dorothy의 둘째 딸 Mabbie도 정신분석 치료를 받기 시작했다.

1926년 가을, Sweetser 부부 역시 둘째 딸 Adelaide를 정 신분석에 참여시키기로 결정하고, 비엔나에 있는 Dorothy의 집에 1년간 머물렀다. Dorothy는 Peter Blos와 함께 그녀의 집을 학교처럼 꾸몄다.

\section{Burlinghams 가족의 정신분석}

Dorothy Tiffany Burlingham

처음 Dorothy의 정신분석은 Sigmund Freud의 친구이자 동료인 Theodor Reik이 진행하였다. 후에 Reik이 비엔나 학 계에서 입지가 흔들리자, 1927년 초부터는 Sigmund Freud가 직접 Dorothy의 정신분석을 진행했다. Sigmund Freud는 Dorothy의 상태가 "공포를 동반한 히스테리 또는 강박증적 신경증(hysterical or obsessive neurosis with fear)"이라고 하였다. Dorothy는 남편 Robert가 비엔나에 방문할 때 정신 신체질환을 않는데, 이를 통해 그녀의 정신적 문제가 남편 Robert와 관련이 있음을 알 수 있다. Sigmund Freud는 Dorothy가 남편으로부터 독립하려면 성욕을 승화시켜야만 한다고 했다(Burlingham 1989). 즉, 남편에게 돌아가고 싶은 마음과 아이들에 대한 책임감 사이에서 갈등하는 Dorothy 의 문제가 성욕을 자제함으로써 해결된다고 진단한 것이다. 또한 그녀의 강박증적 신경증의 원인을 Dorothy의 언니 Annie의 죽음과 어린 시절 유모에게 학대당한 트라우마에 서 찾았다. Sigmund Freud의 이론에 따르면 여섯 살 무렵에 성욕이 줄어들고 오이디푸스기를 겪으며 초자아가 형성되 는데, Dorothy는 이 시기에 언니의 죽음과 유모의 학대를 경험하였고, 이 때문에 강박증적 신경증이 생겼다고 해석하 였다. 
큰아들, $\mathrm{Bob}$

$\mathrm{Bob}$ 의 정신분석학적 문제는 크게 두 가지였다. 첫째, 조울 증(manic-depressive) 성향, 둘째, 수동적이고 여성스러운 (passive-feminine) 성격적 특성이다(Burlingham 1989). $\mathrm{Bob}$ 은 적대적 행동이나 비행을 저지르고 나서 후회하고 우 울해지는 것을 반복하였다. 이는 아버지 Robert의 조울증과 관련된 유전질환으로 생각된다. 또한 그는 아버지에 대한 이 중적 태도(double attitude)를 보였는데, 어머니와의 관계에 있어서는 아버지가 죽기를 바라면서 자신의 동성애(homosexual love) 대상으로는 아버지가 살아있기를 바란 것이다. 이 때문에 Anna는 Bob의 공격성을 줄이고 성 정체성 회복 을 목표로 정신분석을 진행했다.

둘째 딸, Mabbie

Mabbie의 정신분석에서 가장 중요했던 부분은 충성심 갈 등(loyalty conflict)이었다(Burlingham 1989). Mabbie의 경 우 유모에 대한 충성심이 너무 강해 분석치료에 어려움이 있 었다. Mabbie의 정신분석은 진전을 보이지 않았는데, Anna 는 이 같은 저항이 Mabbie가 유모와 애착을 형성하고 있기 때문이라는 것을 발견하였다. Anna는 분석을 진행하기 위해 서 반복적으로 유모를 비판하면서 유모와의 신뢰를 깼고, 비 로소 정신분석을 진행할 수 있었다.

\section{Dorothy의 정신분석에 대한 학문적 관심}

Dorothy는 1926년부터 1927년까지 소아정신분석학에 관 한 Anna의 네 번의 강의에 참석했다. 이는 그녀가 정신분석 학에 대해 학문적 열의가 생겼음을 시사한다. 소아정신분석 세미나의 초기 참가자 멤버인 Anny Rosenberg Angel(별명 Katan), Marie Briehl, Jenny Pollak Waelder, Editha Sterba, Grete Bibring, Marianne Rie Kris, Anna Maenchen 등과 함께 세미나에도 참석했다. 정신분석을 해본 임상경험도 없 고 심지어 대학교육도 받지 않은 Dorothy가 세미나에 참석 할 수 있었다는 점은 오늘날 정서로 이해하기 힘들지만, 그 당시에는 정신분석에 관한 표준화된 교육 과정이 없었기 때 문으로 생각된다. Dorothy는 세미나의 정식 회원으로 등록 하지는 않고 참가만 하여 세미나를 듣고 내용을 익히는 데 집중했다. Anna가 Eva Rosenfeld에게 쓴 편지에서 "Dorothy는 우리 세미나의 멤버가 되고 싶어 하고 스스로 많은 노 력을 하고 있다.”라고 언급하였다(Burlingham 1989).

\section{Matchbox school(Hietzing school)}

1926에서 1927년으로 넘어가는 겨울 Dorothy와 Anna, Peter Blos, Eva Rosenfeld는 정신분석적 가치를 지향하는 학교
를 설립하였다(Burlingham 1989). Dorothy의 경제적 뒷받 침이 학교를 설립하고 운영하는 원동력이 되었다. Peter Blos 는 본인이 독일에 살 때 학교 친구였던 Erik Homburger(훗 날 Erik Erikson)를 초대하였고, 이들은 Rosenfeld 집 뒷마 당에 2층짜리 건물을 짓고 학교를 세웠다. Dorothy의 자녀 들과 Sweetzer의 자녀들을 포함하여 15 20명 정도가 학교 학생이었다. 학교가 정신분석적 가치를 지향하기는 했지만 모든 학생들이 정신분석을 받는 것은 아니었으며, 학교 자체 는 교육적 성격이 더 강했다. 학교에서 Erik은 예술, 독일어, 역사, Peter는 지리와 생물학, Dorothy와 Marie Briehl(소아 정신분석가)은 영어, Herr Goldscheider는 라틴어, 산수, 기 하학을 가르쳤다.

\section{Peterjordanstrasse 72 번지로의 이사 및 비엔나 정착}

Dorothy가 비엔나에 도착한 후 세 번째로 이사를 간 곳은 Peterjordanstrasse 72번지이다. 앞서 거주했던 두 저택은 빌 린 것이었지만 이 집은 구입하였고 이를 통해 Dorothy가 비 엔나에 정착하기로 마음을 굳혔음을 알 수 있다. Peter Blos 역시 Dorothy의 새 집 마련은 Anna와의 관계가 Dorothy에 게 중요해졌음을 의미한다고 언급했다(Burlingham 1989). 이 무렵 Dorothy의 네 자녀는 모두 Anna에게 정신분석을 받 고 있었으며, Dorothy 본인 역시 Sigmund Freud에게 정신 분석을 받았다. Dorothy는 Freud 가문과 깊은 관계를 맺고 동료들과 함께 학교를 만들어 운영하는 등 비엔나 생활에 완벽하게 적응하였다. Dorothy의 소아정신분석에 대한 학 문적 욕구를 채워 주기에도 고향인 뉴욕보다 비엔나가 적당 했으며, 비엔나를 꿈의 도시라 부르며 비엔나에서의 삶에 매 우 만족하였다. 또한 끊임없이 본인을 괴롭히는 남편 Robert 및 시아버지와의 갈등을 줄이고, 남편이 네 자녀에게 미치는 영향력을 최소화한다는 점에서도 비엔나는 뉴욕보다 좋은 선택지였다. 그녀는 이 같은 복합적인 이유로 비엔나에 정착 하였고 정신분석학자로서의 새로운 삶을 시작하였다.

\section{학문적 활동의 본격적 시작(1929 1932)}

1929년 가을 Burlingham 일가는 Peterjordanstrasse 72번 지에서 Bergasse 아파트로 또 다시 이사했다. 이 아파트는 한 때 Freud 가족이 살았던 곳으로 Sigmund Freud와 Anna의 진료실과 가까웠다. Dorothy는 이곳에서 본격적으로 학문 활동을 시작했으며, 주 1 회 참석하던 세미나에 주 3 회 참석 하며 소아정신분석뿐 아니라 성인정신분석에 관한 주제에 도 관심을 보였다. 또한 정신분석 수련을 받기 시작했는데 첫 번째 분석대상은 August Aichhorn의 아들 Walter와 장님 소녀 등이었다. 1930년 5월 4일, Ernst Simmel이 운영하는 
Psychoanalytic sanatorium에 다녀오기 위해 Sigmund Freud와 함께 베를린을 방문하는 등 학문적 관심을 꾸준히 이 어갔다. 1932년 그녀는 "Child Analysis and the Mother" (Burlingham 1935)를 발표하며 비엔나 정신분석학회(Vienna Psychoanalytic Society)의 정식회원이 되었다(Table 2). 모자 관계(mother-child relationship)는 Dorothy의 주 관심 분야 였다. 이 주제는 향후 50년 가량 이어진 그녀의 학문적 활동 을 관통하는 하나의 큰 줄기가 된다. Dorothy는 아이와 엄마 사이에는 특별한 공감 능력이 형성되어 있다고 생각했다. 어 린 아기는 엄마의 감정을 파악하고 민감하게 반응할 수 있는 능력이 있으며, 유년기에 형성된 모자관계는 아이의 무의식 과 엄마의 무의식을 연결한다. 예를 들면, 엄마의 신경증, 강 박증, 불안증 등이 아이의 정서 발달에 영향을 끼친다는 것 이다. Dorothy 본인이 Sigmund Freud에게 정신분석을 받 으며 초점을 맞추었던 주제였으며, 자신의 아이들 정신분석 에 있어서도 강조했던 부분이기도 하다. 따라서 Dorothy는 소아정신분석을 진행할 때 아이의 가정 환경 전체를 다루어 야 할 필요성을 강조하였다.
스위스로 망명(1933 1938)

1933년 히틀러가 독일을 점령하고, 1934년 비엔나 사회민 주주의자 2월 봉기가 일어나는 등 국제 정세는 매우 급박하 게 돌아갔다. 이 무렵 Dorothy의 네 자녀들이 Robert가 있 는 미국을 방문하기도 하고, 남편과 시아버지가 비엔나에 오 기도 하며 자주 교류하였다. 당시 Dorothy의 자녀들은 10대 였고, 대학 진학 문제를 고민하였다. 남편 Robert와 Dorothy 는 여전히 이혼은 하지 않은 채 별거하며 지냈고, 특히 큰아들 $\mathrm{Bob}$ 은 부모 갈등의 영향이 가장 컸던 아이였다. Bob은 1936 년 9월 Harvard 대학에 입학하였고, Tinky는 Bennington 대 학, Michael은 MIT를 목표로 하는 등 네 자녀들의 꿈은 비엔 나가 아닌 미국에 있었다. 1938년 3월 15일, 비엔나를 점령 한 나치 정권은 정신분석학회지를 출판하던 건물을 점거하 고 편집위원장을 맡고 있던 Anna의 오빠 Martin을 체포한다. 이 당시 Dorothy는 결핵으로 병원에서 안정을 취하는 중이 었다. 몸이 불편했던 그녀는 Sigmund Freud가 안전하게 망 명할 때까지 큰아들 Bob과 함께 비엔나에 머물렀다. 한편 MIT에 진학하고 싶어 하는 막내아들 Michael을 미국으로 보내고 MIT 교수인 친구 Alfred de Forest에게 입학 준비를

Table 2. Bibliography of Dorothy Burlingham and Anna Freud after they had met

\begin{tabular}{|c|c|c|c|c|}
\hline Year & Dorothy Burlingham & Age & Anna Freud & Age \\
\hline 1927 & $\begin{array}{l}\text { Finds Hietzing school and starts pediatric } \\
\text { psychoanalysis }\end{array}$ & 35 & $\begin{array}{l}\text { Finds Hietzing school and starts pediatric } \\
\text { psychoanalysis }\end{array}$ & 31 \\
\hline 1932 & $\begin{array}{l}\text { Becomes a formal member of Vienna } \\
\text { Psychoanalytic Society }\end{array}$ & 40 & & 36 \\
\hline 1937 & Establishes the Jackson nursery & 45 & Establishes the Jackson nursery & 41 \\
\hline 1938 & Moves to London & 46 & Moves to London & 42 \\
\hline 1939 & & 47 & Death of S. Freud & 43 \\
\hline 1941 & $\begin{array}{l}\text { Moves to Maresfield Garden } 20 \\
\text { Starts the Hampstead war nursery }\end{array}$ & 49 & Starts the Hampstead war nursery & 45 \\
\hline 1944 & $\begin{array}{l}\text { Stops attending London Psychoanalysis Society } \\
\text { because of the confrontation of opinions }\end{array}$ & 52 & $\begin{array}{l}\text { Is elected as vice-president of the International } \\
\text { Psychoanalytical Association }\end{array}$ & 48 \\
\hline 1947 & Starts the Hampstead child therapy course & 55 & Starts the Hampstead child therapy course & 51 \\
\hline 1950 & & 58 & $\begin{array}{l}\text { Is awarded with an honorary doctorate at Clark } \\
\text { University }\end{array}$ & 54 \\
\hline 1952 & $\begin{array}{l}\text { Opens the Hampstead child therapy clinic and } \\
\text { introduces the pediatric psychoanalysis }\end{array}$ & 60 & $\begin{array}{l}\text { Opens the Hampstead child therapy clinic and } \\
\text { introduce the pediatric psychoanalysis }\end{array}$ & 56 \\
\hline 1953 & First nervous breakdown of Robert ("Bob") & 61 & & 57 \\
\hline 1970 & $\begin{array}{l}\text { Death of Robert ("Bob") Burlingham Jr at the age } \\
\text { of } 44\end{array}$ & 78 & Death of younger brother Ernest & 74 \\
\hline 1973 & Death of twin sister Julia de Forest Tiffany & 81 & & 77 \\
\hline 1974 & $\begin{array}{l}\text { Death of twin sister Louise Comfort Tiffany } \\
\text { Death of Mary ("Mabbie") Tiffany Burlingham }\end{array}$ & 82 & & 78 \\
\hline 1979 & November 19 , passes away & 87 & Attends the first Hamstead Symposium & 83 \\
\hline 1982 & & & October 9 , passes away & 86 \\
\hline
\end{tabular}


도와 달라고 부탁하였다. 한편 새로운 나치 정권은 비오스트 리아인(non-Austrian)들이 외화 자산을 소유하는 것을 금지 하였고, Dorothy 역시 전 재산을 몰수당하거나 감옥에 가거 나 혹은 망명해야 하는 선택의 기로에 놓이게 되었다. 뉴욕 에서 제네바로 온지 13년만인 1938년 4월 1일, Dorothy는 결국 스위스 취리히로 떠났고, 이후 티치노에 정착하였다.

\section{런던 생활의 시작}

1938년은 Dorothy 인생에 있어서 견디기 힘든 해였다. 꿈 의 도시라고 할 만큼 비엔나에서의 삶에 만족했던 Dorothy 가 나치 정권을 피해 스위스를 거쳐 런던으로 망명해야 했기 때문이다. 1938년 5월 5일 Dorothy는 비엔나로 돌아가 Anna 의 이모, Minna Bernay를 모시고 런던으로 갔다. 한편 큰딸 Mabbie의 결혼식 직후인 1938년 5월 28일, 남편 Robert가 자 살하였고 이는 Dorothy에게 큰 슬픔이었다. 당시 46세였던 Dorothy는 남편의 죽음에 대한 책임감으로 힘들어 했으나 Freud 가족과 자녀들의 위로로 버틸 수 있었다. 1938년 가을, Dorothy는 Maresfield Gardens 2번지로 이사했다. 당시 같이 살았던 사람은 Tinky, Bob, 그리고 그해 Bob과 결혼한 Mossik Sorensen이었다. 이때 큰딸 Mabbie와 사위 Simon Schmiderer은 영국에서 건축을 전공하고 있었고, 사위는 훗날 뉴욕과 푸에르토리코에서 활동하였다. 막내아들 Michael은 유일하게 영국이 아닌 미국에 거주하며 MIT에 진학하였다. Dorothy가 런던에 정착한 몇 주 후 Freud 가족 역시 런던으 로 이사를 왔다. 한편 1923년부터 암 투병 중이었던 Sigmund Freud는 1938년 9월 8일 큰 수술을 받지만, 회복되지 못했 고 1939년 9월 23일 사망하였다. 많은 사건들이 있었던 1938 년은 Dorothy와 Freud 가족에게 고난의 해가 되었다. 이로부 터 3년 후인 1941년, Dorothy는 Freud 가족이 살고 있는 Maresfield Garden 20번지로 이사를 하고 이곳에서 여생을 보 냈다.

\section{학문 활동의 재시작}

1938년 10월 20일 Dorothy는 영국 정신분석학회(British Psychoanalytic Society)에 간결한 서신을 보냈다. 그 내용은 "우리의 정신분석학회 모임은 시작되었으며 비엔나를 그 어 느 때보다 그리워하고 있다."였다(Burlingham 1989). 또한 1942년 1월 11일에 큰 며느리 Mossik에게 "이곳의 정신분석 학계는 매우 끔찍하고 진정으로 정신분석을 위하는 사람은 몇 명밖에 되지 않는다.”라고 했다. 이를 통해 Dorothy와 런 던 정신분석학회가 대립했음을 알 수 있는데, 당시 런던 정 신분석학회를 이끌던 Melanie Klein과 정신분석에 접근하 는 방식이 이론적으로, 그리고 기술적으로 달랐다. Dorothy
와 Anna는 런던 정신분석학회에 참여하기보다, 전통적으로 그들이 해오던 수요일 저녁 세미나를 Maresfield Garden 20 번지에서 계속 이어갔다. 또한 잠복기 이전 아이들에 대한 치 료는 피해야 한다고 주장했던 Klein과는 달리 소아세미나를 진행하였고, 소아정신분석에 대한 열정을 이어갔다. 1940년 5월 1일 Dorothy는 세 명의 아이들을 정신분석하고, 처음으 로 분석가들을 교육하는 일도 시작했다. 분석가들을 교육하 는 것은 미래의 분석가들에게 영향력을 끼칠 수 있는 일이기 에, Dorothy는 교육에 매우 흥미를 느꼈다. 한편 1940년 7월 Anna의 오빠 Martin과 Martin의 아들 Ernest 등이 비엔나 에서 수감되고, 이외 Freud 가족 중 상당수가 나치 정권의 핍 박에 희생되었다. Anna의 막내삼촌인 Alexander는 캐나다 로 이민을 떠났고, 큰고모 Anna Freud(정신분석가 Anna Freud와 동명이인)는 1883년 Eli Bernays와 결혼하여 1892년 미국으로 이민을 떠나서 안전하게 살고 있었으나, 고모 다섯 명 중 셋(Regine Debora, Maria, Pauline)은 1942년 Treblin$\mathrm{ka}$ 유태인 수용소 가스실에서 사망하였으며, Esther Adolfine는 1943년 Theresienstadt 수용소 가스실에서 죽었다 (Bahn 2011). 이런 상황을 고려해 볼 때 자녀들이 있는 미국 으로 망명하는 것이 Dorothy에게는 안전한 선택이었을 것이 다. 하지만 Dorothy와 Anna는 꿋꼿이 런던 잔류를 고집하 였다. 그 이유에 대해 Dorothy는 "우리가 미국에서의 분석 활 동에 만족할 수 없었기 때문이다.”라고 말하였다(Burlingham 1989). 이를 통해 그들의 인생에 있어서 학문에 대한 열정이 그 무엇보다 우선 순위였음을 알 수 있다.

\section{Hamstead nursery}

1940년 나치군들의 공격이 영국까지 확대되고 영국군과 나치군의 전쟁이 시작되면서 많은 아이들이 보호소로 오게 되고, Anna와 Dorothy는 아이들을 돌보며 본인들의 연구 활 동을 지속해 나가기로 결심하였다. 1941년 시작한 Hamstead nursery에서의 활동은 Anna와 Dorothy가 영국에 정착하는 계기가 된다. 같이 근무하는 직원은 Josephine Stross(소아과 의사), Heddy Schwartz(이전 관리인), Ilse Hellman(Heddy Schwartz의 후임자), 그리고 Sophie와 Gertude(간호사, 요 리사) 등이었다. 전쟁이 아이들에게 미치는 영향은 다양했 다. 전쟁 때문에 부모와 아이들이 분리되는 것이 아이들의 정 서에 영향을 미치는 주된 요인이었으며, 이 충격으로 건강한 아이가 눈 주위에 강박장애로 인한 틱이 생기기도 했다. 이 곳에서 전쟁 고아들을 돌보며 관찰한 내용들은 Dorothy가 작성한 원고 "Young Children in War-Time: a Year's Work in a Residential War Nursery"(Burlingham과 Freud 1942), "Infants without Families: the Case for and Against Residential 
Nurseries"(Burlingham과 Freud 1944)의 기반이 되었다(Table 3).

Hampstead child therapy course 시작 및 학문 활동의 정점 당시 영국 정신분석학회의 규정에 따르면 성인정신분석학 과정을 수료한 사람만이 소아정신분석 프로그램을 시작할 수 있었고, 따라서 대학 졸업 후 8년의 수련 과정을 거쳐야 소아정신분석을 시작할 수 있었다. 물론 의학을 공부하지 않 은 사람들도 정신분석에 제약은 없었으나, 대부분의 사람들 이 의과대학까지 졸업한 후 정신분석에 입문하였으므로 소 아정신분석을 배우기 위한 시간이 너무 길었다. 1952년, Dorothy와 Anna는 대학 졸업자들이 5년의 집중교육을 받은 후 소아정신분석을 할 수 있는 교육 과정을 만들었다. Hampstead child therapy center에서는 45명의 정신분석가들에 의 해 50 70여 명의 아이들이 치료를 받고 있었다. 이렇듯 센
터에서는 연구, 치료, 그리고 교육의 세 가지 부분이 모두 이 루어졌다.

Dorothy는 중요한 학문적 성취를 Hampstead child therapy center에서 이룬다. 정신분석에 입문할 당시 Dorothy의 관심 영역은 모자관계였다. 이후 이 주제를 더욱 확장하여 쌍둥이 정신분석에 흥미를 갖게 되었는데, Dorothy에게 쌍 둥이 언니인 Comfort와 Julia가 있었다는 점과 전쟁 당시 고 아원에서 만났던 네 쌍의 쌍둥이들이 그녀가 쌍둥이 정신분 석에 흥미를 갖는 계기가 되었다. 쌍둥이가 서로에게 미치는 영향, 그리고 각각의 쌍둥이들과 엄마와의 관계가 서로에게 미치는 영향 등이 그녀의 주된 연구 주제였다. 그녀는 "The Fantasy of Having a Twin”(Burlingham 1945) 발표를 시작으 로 쌍둥이 정신분석에 대한 관심을 이어갔다. 한편 1941년 에는 맹아(blind child)에 대한 정신분석을 시작하였고, 맹아 는 향후 20 년간 그녀의 학문 활동에 관심 분야가 되었다.

Table 3. Publication of Dorothy Burlingham

\begin{tabular}{|c|c|}
\hline \multirow{6}{*}{$\begin{array}{l}\text { Mother-child } \\
\text { relationship }\end{array}$} & Child analysis and the mother (1935) \\
\hline & Present trends in handling the mother-child relationship during the therapeutic process (1951) \\
\hline & Simultaneous analysis of mother and child (1955) \\
\hline & The theory of the parent-infant relationship-contributions to discussion (1962) \\
\hline & Empathy between infant and mother (1967) \\
\hline & The preoedipal infant-father relationship (1973) \\
\hline \multirow[t]{4}{*}{ Twin study } & The fantasy of having a twin (1945) \\
\hline & Twins; observations of environmental influences on their development (1946) \\
\hline & The relationship of twins to each other (1949) \\
\hline & $\begin{array}{l}\text { A study of identical twins; their analytic material compared with existing observation data of their early } \\
\text { childhood (1963) }\end{array}$ \\
\hline \multirow{11}{*}{$\begin{array}{r}\text { Blind children } \\
\text { development }\end{array}$} & Psychic problem of the blind (1941) \\
\hline & Some notes on the development of the blind (1961) \\
\hline & Hearing and its role in the development of the blind (1964) \\
\hline & Some problems of ego development in blind childeren (1965) \\
\hline & Developmental consideration in the occupations of the blind (1967) \\
\hline & Occupations and toys for blind children (1968) \\
\hline & The re-education of a retarded blind child (1968) \\
\hline & Psychoanalytic studies of the sighted and the blind (1972) \\
\hline & Special problems of blind infants. Blind baby profile (1975) \\
\hline & To be blind in a sighted world (1979) \\
\hline & Psychoanalytic observations of blind children (1980) \\
\hline \multirow[t]{6}{*}{ Etcetera } & Ein kind beim spiel (A child at play) (1932) \\
\hline & Mitteilungsdrang und geständniszwang (The urge to confide and the compulsion to confess) (1934) \\
\hline & Adventures in self-discovery: by David Seabury (1938) \\
\hline & Young children in war-time: a years's work in a residential war nursery (1942) \\
\hline & Infants without families: the case for and against residential nurseries (1944) \\
\hline & Precursors of some psychoanalytic ideas about children in the sixteenth and seventeenth centuries (195 \\
\hline
\end{tabular}




\section{맹아 관련 연구}

그녀는 맹아와 관련된 논문을 10편 출간했고, "Psychoanalytic Studies of the Sighted and the Blind"(Burlingham 1972)라는 제목으로 책을 출판하기도 하였다(Table 3, Appendix). 정신분석학적으로 맹아에 접근한 그녀의 시도가 의 미 있는 이유는 희소성 때문이다. 그녀 이전에 맹아에 대해 정신분석학적으로 접근한 논문이 없었고, 이후에도 맹아를 다룬 정신분석 연구는 비교적 적은 편이기에 Dorothy의 맹 아연구 업적은 주목할 만하다. 그녀가 맹아에 대해 처음 작 성한 논문은 "Psychic Problems of the Blind"(Burlingham 1941)였다. 그녀는 비엔나 어린이 보호시설(Israelitisches Blindeninstitut, Hohe Warte)에 맡겨진 맹아 Sylvia의 발달 과정을 오랜 시간 관찰하고 정신분석을 진행했다. Sylvia는 임균감염으로 출생 시부터 시력을 잃었다. Dorothy는 시각 결핍이 발달 과정의 특정 부분에까지 결핍을 초래할 것이라 는 관점으로 첫 번째 원고를 작성하였다. 또한 이 경험을 바 탕으로 하여 1960 1970년대에 맹아에 관한 논문들을 다수 발표했다. Dorothy와 Anna가 설립한 Hamstead Clinic 교육 담당 부분에는 맹아를 정신분석하는 파트가 있어서 주로 특 정 맹아를 지속적으로 관찰한 후, 정신분석 내용을 기술하는 방식으로 논문들을 작성하였다. 맹아 연구에 대한 주제는 맹 아의 자아 형성 과정이 정상아와 어떻게 다른지, 시각 외 감 각의 발달과 사용, 맹아의 발달 과정에 적합한 장난감 개발 등이었다.

\section{생의 마감}

큰아들 Bob은 아버지 Robert와 마찬가지로 조증, 우울증 시기를 주기적으로 겪으며 감정적으로 힘든 인생을 살았다. Anna는 정신분석학적 관점에서 Bob을 치료하려고 하였으 나, 그의 고통은 생화학적, 또는 유전적 원인에 의한 것이었 기에 큰 효과가 없었다. 그는 천식과 폐기종을 않고 있음에도 계속 담배를 피웠으며, 1970년 1월(44세) 천식으로 인한 심 장마비로 사망한다. 사업차 Puerto Rico에 살고 있던 Dorothy의 딸 Mabbie는 1974년 어머니가 있는 런던으로 온다. 이 당시 Mabbie의 남편 Simon은 은퇴할 나이가 되기 전에 실직하여 우울감에 빠졌다. 이에 영향을 받아 Mabbie 역시 우울증을 겪었고, 결국 수면제를 과다 복용하여 자살하였다. 이 무렵 쌍둥이 언니 Julia와 Comfort도 세상을 떠남으로써 Dorothy는 많은 상실을 경험하였다. 사랑하는 사람들의 죽 음을 지켜보는 것은 Dorothy에게 고통이었다.

1979년, Dorothy 역시 시름시름 않기 시작했다. 그해 11월 Annual Hampstead Clinic 연례 심포지엄에 참석하고 며칠 후인 11월 20일, 87세의 나이로 Dorothy는 세상을 떠났다. 그
녀의 시신은 Anna와 Sigmund Freud 등 Freud 가족의 시신 이 묻혀 있는 런던 Golders Green Crematorium에 안장되었다.

\section{결 론}

Dorothy와 Anna가 가까워지게 된 가장 중요한 이유는 서 로에게 도움이 되었기 때문이다. Dorothy는 큰아들을 치료 해 줄 사람이 필요했고 그 답을 Anna에게서 찾을 수 있었다. Dorothy는 자녀 네 명이 모두 정신분석을 받도록 하고 본인 역시 정신분석을 받는다. 그녀는 아이들의 분석치료를 주제 로 Anna와 자주 토론하며 친분을 쌓았다. Anna는 Bob의 치 료자로서 자연스럽게 Dorothy의 친구가 되고, 학문적 성장 을 이끌어 줄 동료로서의 역할도 하게 된다. 이로써 단순한 치 료적 관계에서 개인적 관계로 발전한다.

Anna의 입장에서도 Dorothy는 꼭 필요한 사람이었다. 일 단 Dorothy는 큰아들 Bob의 치료를 위해 대서양을 건너 비 엔나까지 왔다. 당시 정신분석은 시작된 지 얼마 되지 않은 신생 학문이었지만, Dorothy는 Anna를 믿고 본인의 네 자녀 를 맡겼다. Anna에 대한 Dorothy의 믿음은 Anna의 마음을 얻기에 충분했을 것이다. 자식이 없었던 Anna는 Dorothy와 함께 온 네 명의 아이들을 분석하며 교육과 부모의 역할까지 담당하였고, Anna는 그동안 느껴보지 못한 부모의 기분을 느 끼게 된다. 네 명의 아이들에게 부모의 역할을 해주면서 Anna 는 분석교육학적 이론을 적용하고 발전시킬 기회를 얻었다.

시작은 필요에 의한 만남이었으나 두 사람의 관계는 가족 그 이상이었다. 물리적 및 정서적 지지를 통해 두 사람은 각 자 인간적 성숙은 물론, 소아정신분석의 발전에도 기여하였다.

\section{Acknowledgments}

This work was supported by a grant from the Korea Mental Health Technology R \& D Project (HM15C1084).

\section{Conflicts of Interest}

The authors have no financial conflicts of interest.

\section{REFERENCES}

Bahn GH. Study of Anna Freud's life. Psychoanalysis 2011;22:83-94. Burlingham DT. Child analysis and the mother. Psychoanal Q 1935;4: 69-92.

Burlingham DT. Psychic problems of the blind. Am Imago 1941;2:4385.

Burlingham DT. Psychoanalytic studies of the sighted and the blind. New York: International Universities Press; 1972.

Burlingham DT. The fantasy of having a twin. Psychoanal Study Child 1945;1:205-210.

Burlingham DT, Freud A. Infants without families: the case for and against residential nurseries. New York: International University Press; 1944.

Burlingham DT, Freud A. Young children in war-time: a year's work in 
a residential war nursery. London: Allen \& Unwin;1942.

Burlingham MJ. The last Tiffany: a biography of Dorothy Tiffany Burlingham. New York: Atheneum;1989.

Geissmann C, Geissmann-Chambon C, Geissmann P. Histoire de la psychanalyse de l'enfant: mouvements, idées, perspectives. Paris: Ba- yard;1992.

Lynn DJ, Vaillant GE. Anonymity, neutrality, and confidentiality in the actual methods of Sigmund Freud: a review of 43 cases, 1907-1939. Am J Psychiatry 1998;155:163-171. 